\title{
Stability Parameter Analysis and Deformation Simulation of Subway Foundation Pit
}

\author{
Shiwei Hou ${ }^{1, a^{*}}$, Shaopo Guo ${ }^{1, b}$, Shihe Ma ${ }^{1, c}$ and Xuli Liü,d \\ ${ }^{1}$ School of Civil Engineering, Shenyang Jianzhu University, Shenyang 110168, China \\ ahsw1375@126.com, b1029403281@qq.com, c865259103@qq.com, d649445620@qq.com
}

Keywords: Foundation pit; Stability parameter analysis; Strength reduction; Subway

Abstract. Based on the strength reduction method, the deformation process of subway foundation pit was predicted, and the stability parameters were analyzed. The analysis parameters contain the settlement displacement of soil, lateral displacement of the underground continuous wall, and safety factor. It is to simulate the process of dynamic construction of foundation pit and the foundation pit construction is analyzed longitudinally. Each parameter in a state of foundation pit with the shear strength reduction technique is analyzed, and the foundation pit construction is analyzed horizontally. The deformation process and failure mode of soil and supporting system are studied by using of the shear strength reduction technique and the birth and death element function, and it will provide a reference for guiding the construction of practical engineering.

\section{Introduction}

Excavation engineering is a comprehensive system, which relates to the hydrological geology, structure, rock and soil mechanics and percolation mechanics. Either in the construction technique or theoretical basis, excavation engineering is a complicated subject. In order to meet the needs of national economic development, the excavation engineering of subway station shows a characteristic of large, deep, tight and close [1]. The deep excavation will cause stress changes in the surrounding soil and lead uneven settlement of the surrounding soil, which may bring losses to the society and economy. So, it is important to research the stability on supporting structure in the subway station excavation.

\section{Research Method on Stability of Foundation Pit}

The stability of the foundation pit is affected by various factors, including the soil physical and mechanical properties, retaining wall stiffness, wall depth, supporting conditions (stiffness, material, prestress), groundwater (underground seepage) and foundation pit excavation method.

The strength reduction method was first proposed by Zienkiewicz et al. The shear strength reduction coefficient is defined as the ratio of the maximum shear strength and the actual shear stress under the premise that the external load is kept constant. Assuming that all soils in the slope provide the same shear strength, the shear strength coefficient will be the same as the slope stability factor in the traditional analysis, which is conceptually equivalent to the stability safety factor of the limiting equilibrium method [2]. The principle of strength reduction is as follows:

$$
\varphi_{\mathrm{m}}=\arctan \left(\frac{\tan \varphi}{\mathrm{F}_{\mathrm{r}}}\right), \quad c_{m}=\frac{c}{F_{r}}
$$

Meng Qingyin [3] analyzed the reliability of foundation pit excavation based on Rosenblueth statistical moment method. He used the elastic-plastic finite element method to simulate the excavation and support of the foundation pit, and calculated the safety factor after excavation by the strength reduction method. Tang Xiaosong [4] used the finite element strength reduction rule to analyze the plastic deformation of various slope under different slope safety factors, which showed the whole process of sliding surface deformation and slope failure and revealed the failure mechanism of the slope. Zhang Yangyang [5] discussed the slope instability criterion based on the strength reduction method. Under the consideration of the practicality and simplicity, he proposed to adopt displacement mutation and plastic zone coalescence as the criterion of slope instability, 
which would make the safety factor closer to actual engineering. Chen Hao [6] applied the element birth-death method function to the excavation of underground chambers. A three-dimensional finite element model was established to realize the dynamic simulation of staged excavation, and the corresponding parameter indexes were obtained. Su long [7] used the element birth-death method to simulate the retaining wall construction process. The deformation of retaining wall and soil under the three conditions of completion, storage and drawdown of the retaining wall were analyzed and the displacement, earth pressure and the axial force distribution were obtained.

For the foundation pit excavation, the limiting equilibrium method in static mechanics was used traditionally. However, the foundation pit excavation is a discontinuous process and cannot be simulated by using the finite element analysis software. By killing and activating the element of the excavation part to simulate the excavation process, the element birth-death method can make a dynamic analysis of the stress-strain relation during the excavation of the foundation pit.

\section{The establishment of numerical model}

Considering the shape of the foundation ditch, construction scheme and material parameters are symmetric, the half foundation ditch section was chosen, and the model size and boundary conditions are set as follows:

(1) X directions: the excavation width of foundation is $20 \mathrm{~m}$, the both sides are 3 times of excavation depth, and the boundary constraints in these directions are $\mathrm{U} 1=0, \mathrm{U} 2 \neq 0$ (U1 is the direction displacement of the $\mathrm{X}$ axis; $\mathrm{U} 2$ is the direction displacement of the $\mathrm{Y}$ axis).

(2) Y direction: the excavation depth of the foundation is $24 \mathrm{~m}$, the bottom is 3 times of excavation depth, and the boundary constraints in these directions are $\mathrm{U} 1=0, \mathrm{U} 2=0$ [8].

The soil constitutive model of the finite element method is the Mohr Kulun model. The silty clay was used in this example, and the soil gravity $\mathrm{r}=20 \mathrm{kN} / \mathrm{m}^{3}$, cohesion $\mathrm{c}=28 \mathrm{kPa}$, internal friction angle $\phi=20^{\circ}$, modulus of elasticity $\mathrm{E}=50 \mathrm{MPa}$, Poisson ratio $\mu=0.3$. The diaphragm wall and supports were considered as elastic materials. For the diaphragm wall, elasticity modulus $\mathrm{E}=2.4 \times 10^{7} \mathrm{kPa}$, Poisson ratio $\mu=0.2$, density $t=2.5 \mathrm{t} / \mathrm{m}^{3}$, thickness $\mathrm{b}=1 \mathrm{~m}$. For the supports, elasticity modulus $\mathrm{E}=1.3 \times 10^{6} \mathrm{kPa}$, Poisson ratio $\mu=0.3$, density $t=0.06 \mathrm{t} / \mathrm{m}^{3}$, thickness $\mathrm{b}=1 \mathrm{~m}$. The distance between adjacent supports was $7.5 \mathrm{~m}$. The soil, diaphragm wall and supports were selected as solid units. The soil element was modified triangular element, and the plane strain element type was CPE6M, which can effectively avoid hourglass problems and self-locking problems. The diaphragm wall and supporting materials were mainly used in the elastic stage, so the twice-completed integral was applied, and the plane strain element type was CPE8, which can avoid self-locking problems under normal circumstances [9].

Strength reduction method setting. The strength reduction method was divided into three steps in the simulation process. The first step was to apply initial crustal stress; the second step was to balance the initial crustal stress; and the third step was to reduce the overall strength of the soil. The displacement of the characteristic point and the passing zone of the plastic zone were the bases for judging critical failure of foundation pit. The excavation process in this example was divided into four steps, so there were 4 strength reduction models.

When all the excavation steps were completed, the displacement curves (lateral displacement curve and horizontal subsidence displacement curve) of the retaining wall were extracted in Fig. 1. After the first step, the maximum displacement of the horizontal surface near the $8 \mathrm{~m}$ of the foundation pit edge is $0.036 \mathrm{~m}$; the maximum value of the lateral displacement near the $7 \mathrm{~m}$ top of the foundation pit is $0.48 \mathrm{~m}$. After the second step, the maximum displacement of the horizontal surface about $6 \mathrm{~m}$ from the edge of the foundation pit is $0.048 \mathrm{~m}$; the maximum lateral displacement near the $17 \mathrm{~m}$ top of the foundation pit is $0.08 \mathrm{~m}$. With the excavation carried out, the dangerous points moved to the edge and the bottom of the foundation pit, and the displacement became larger, and the damage was more serious, which conformed to the actual engineering situation. 


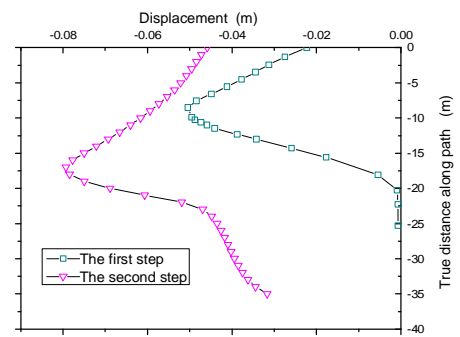

a. lateral displacement of soil profile

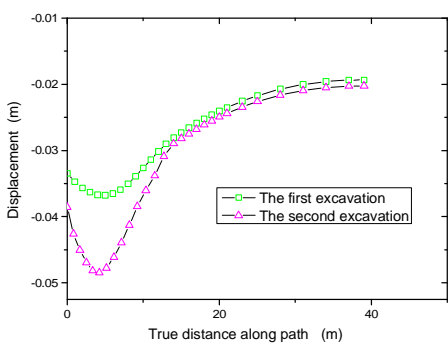

b. horizontal displacement of soil mass

Fig. 1 Displacement of soil behind retaining wall

The safety factors of the foundation pit are shown. The safety factor is 1.24 after the first excavation step; the safety factor is 1.18 after the second step; and the safety factor is 1.09 after the third step. With the process of excavation going on, the safety factor is lower and the probability of foundation pit instability is more and more large.

Establishment of birth-death element model. The simulation process of the birth-death element model was carried out according to the actual construction process of the foundation pit excavation. The first step: apply and balance initial ground stress (Its method is the same as the method of the strength reduction model). The second step: construct the first support. The third step: dig the first part of the soil. The fourth step: construct the second support. The fifth step: dig the second part of the soil. The sixth step: construct the third support. The seventh step: dig the third part of the soil. Under the unsupported condition, the plastic zone variation of the excavation is shown in Fig. 2.

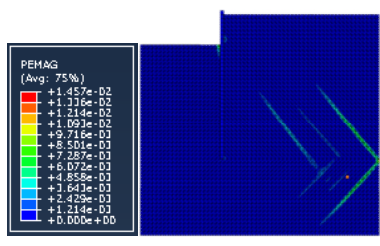

a. Step1

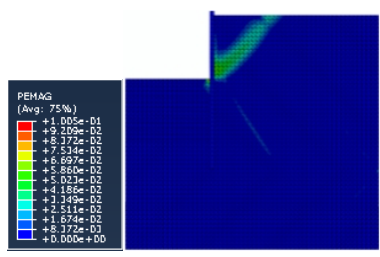

e. Step5

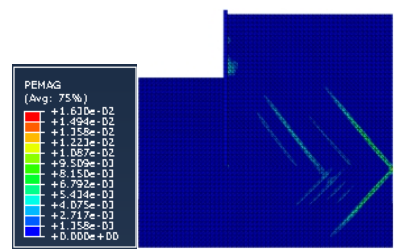

b. Step2

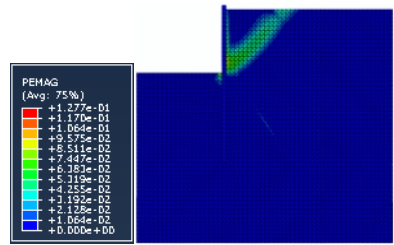

f. Step6

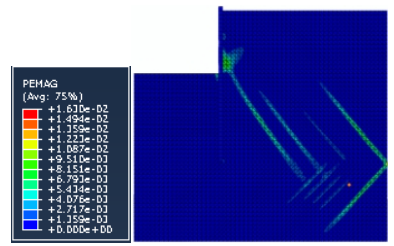

c. Step3

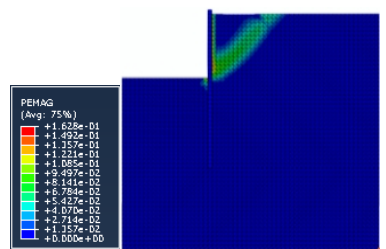

g. Step7

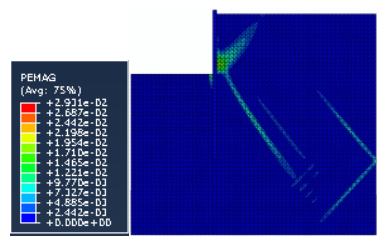

d. Step4

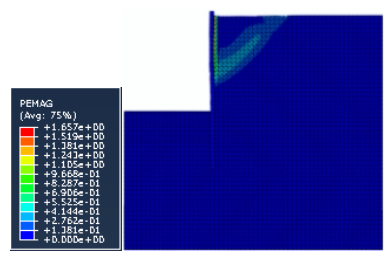

h. Step8

Fig. 2 Variation of plastic zone of foundation pit under unsupported condition

Fig. 2 shows the simulation of actual excavation under unsupported condition. Three excavation steps were set. The plastic point of the foundation pit first appears at the bottom. Because the support condition and the soil strength parameter are weak, the finite element calculation showed the problem that the displacement of the node is too large to converge when the third step is excavated, and the plastic zone has been connected, which can be judged that the soil mass has reached the failure bound. 


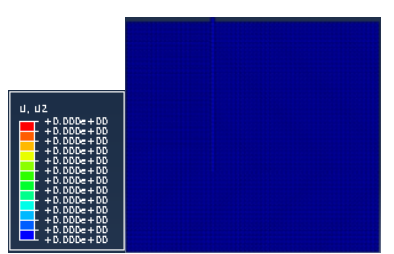

a. Step1

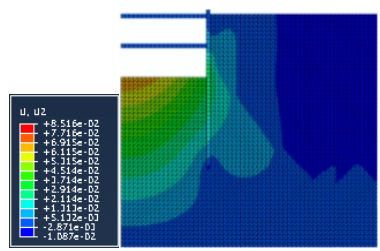

e. Step5

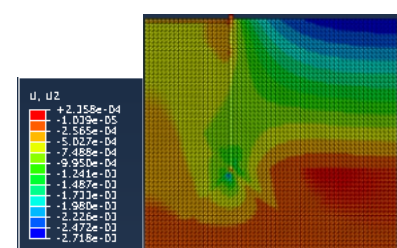

b. Step2

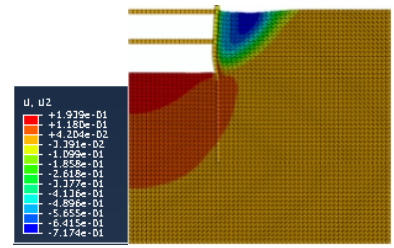

f. Step6

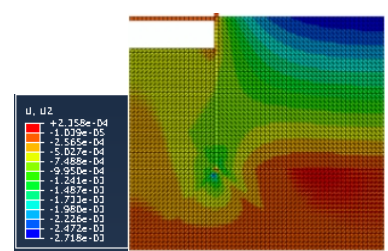

c. Step3

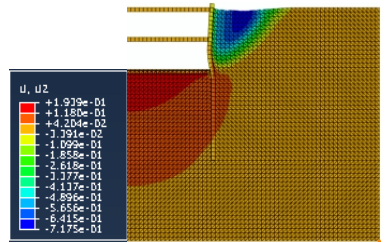

g. Step7

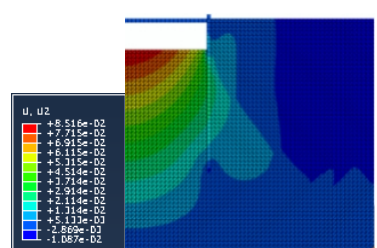

d. Step4

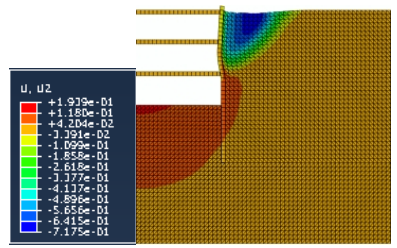

h. Step8

Fig. 3 The horizontal plane of the foundation pit under the support condition

Fig. 3 shows the changes of the horizontal settlement displacement during the excavation under the condition of support. Three excavation steps were set. The plastic point of the foundation pit first appears at the bottom. The time of the plastic zone is later than that of the unsupported condition, because the support is added in time, which improves the ability of the retaining wall to resist the active earth pressure of the soil after the wall. When the third step was excavated, the finite element calculation shows the same problem that the displacement of the node is too large to converge, and there is a mutation in the critical point displacement, at this time, the soil mass reaches the failure bound.

Select a simulation step to analyze the displacement curve of the soil behind the retaining wall. The lateral displacement curve and the horizontal settlement displacement curve of the soil behind the retaining wall are shown in Fig. 4 and Fig.5.

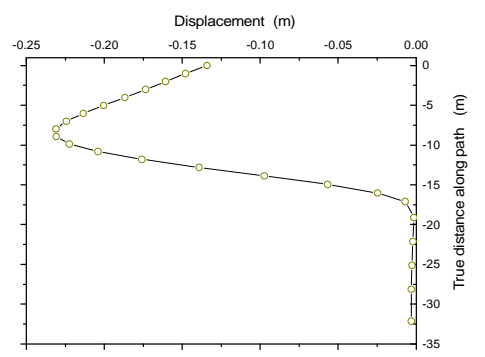

a. Lateral displacement of soil profile

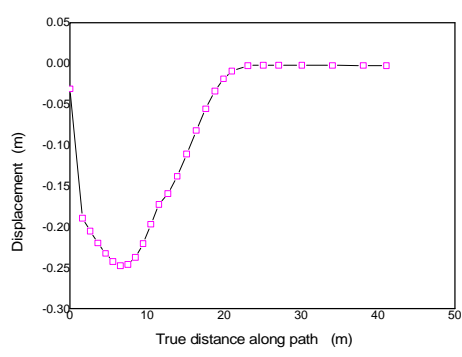

b. Horizontal displacement of soil mass

Fig. 4 Displacement of soil behind unsupported retaining wall

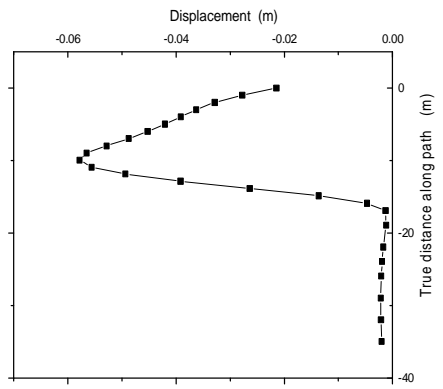

a. Lateral displacement of soil profile

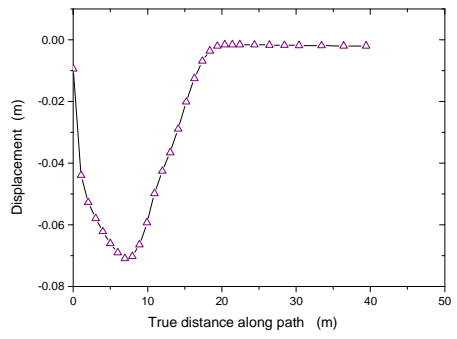

b. Horizontal displacement of soil mass

Fig. 5 Displacement of soil after supporting retaining wall

Under the unsupported condition, the maximum horizontal settlement displacement of the soil behind the retaining wall is about $9 \mathrm{~m}$ from the edge of the foundation pit and its value is $0.25 \mathrm{~m}$. The maximum lateral displacement of the soil behind the retaining wall is about $9 \mathrm{~m}$ from the top of the foundation pit and its value is $0.23 \mathrm{~m}$. Under the support condition, the maximum horizontal 
settlement displacement of the soil behind the retaining wall is about $9 \mathrm{~m}$ from the edge of the foundation pit and its value is $0.07 \mathrm{~m}$. The maximum lateral displacement of the soil behind the retaining wall is about $10 \mathrm{~m}$ from the top of the foundation pit and its value is $0.058 \mathrm{~m}$. When there is support, the ability of the retaining wall to resist the active earth pressure of the soil after the wall is significantly improved, and the maximum settlement range is reduced, which provides a theoretical basis on the influence area of construction settlement for the construction of subway foundation pit.

\section{Conclusions}

Unlike the traditional limiting equilibrium method, the strength reduction method can get not only the stress, displacement and plasticity of the foundation pit system, but also the dangerous sliding surface and the corresponding safety factors, which is of great significance for the practical engineering.

By using the element birth-death method, the construction process of dynamic foundation can be simulated efficiently; the process of stress in the soil excavation can be analyzed accurately; and more bases for the calculation of foundation pit engineering can be provided.

The reduction of strength reduction and the birth-death element in layered soil need to be verified and analyzed. The next step is to develop a reliable mechanical model for the contact between the retaining wall and the soil, research the deformation and stress of the foundation pit system, and apply it to the actual project.

\section{Acknowledgements}

This work was financially supported by the National Natural Science Foundation of China (51308355), Project supported Liaoning Province, colleges and universities outstanding young scholar growth plan (LJQ2014058), Ministry of Housing and Urban-Rural Development of the People's Republic of China Project (2015-K3-025) and Natural Science Foundation of Liaoning Province (20170540736).

\section{References}

[1] Y.Q. Wu: Research on the Numerical Simulation of Deep Foundation Pit of Lanzhou Metro Station in Lanzhou City (MS. Lanzhou University of Technology, China 2013) (In Chinese).

[2] L.H. Chen: China Civil Engineering Journal, Vol.45 (9) 2012, p.136-146 (In Chinese).

[3] Q.Y. Meng: Geotechnical Foundation, Vol.25 (1) 2011, p.70-73 (In Chinese).

[4] X.T. Tang, Y.R. Zheng: Journal of Chongqing University, Vol.36 (10) 2013, p101-113 (In Chinese).

[5] Y.Y. Zhang: Journal of Zhejiang Water Conservancy and Hydropower College, Vol.21 (1) 2009, p.13-15 (In Chinese).

[6] H. Chen: Journal of Wuhan University (Engineering Science), Vol.46 (3) 2013, p.321-327 (In Chinese).

[7] L. Su: Numerical Simulation Analysis of the Influence of Water Retaining on Retaining Wall of Inverted Anchor (MS. Taiyuan University of Technology, China 2015) (In Chinese).

[8] S.F. Gu: Based on the Soil Hole Displacement Reduction Analysis (MS. South China University of Technology, China 2014) (In Chinese).

[9] X.C. Wang: Finite element method (Tsinghua University press, China 2003) (In Chinese).

[10] A.J. Zhang: Rock and soil mechanics, Vol.34 (2) 2013, p.332-337 (In Chinese).

[11] Y.Y. Zhang: Journal of Zhejiang Water Conservancy and Hydropower College, Vol.21 (1) 2009, p.13-15 (In Chinese).

[12] C.S. Huang: Deformation Prediction Method and Engineering Application of Deep Excavation of Metro (Ph.D. Central South University, China 2011) (In Chinese).

[13] M.T. Luan, Y.J. Wu and Y.K. Nian.: Journal of Disaster Prevention and Mitigation Engineering, Vol.23 (3) 2004, p. 1-8 (In Chinese). 
[14] J.J. Li, W.D. Wang and G.E. Di: Rock and Soil Mechanics, (Suppl. 1) 2007, p.633-639 (In Chinese).

[15] Q.W. Duan and Y.J. Wang: Journal of Hydraulic Engineering, Vol.39 (11) 2009, p.1251-1256 (In Chinese). 